\title{
Physiologic responses and gene diversity indicate olive alternative oxidase as a potential source for markers involved in efficient adventitious root induction
}

\author{
Elisete Santos Macedo a , Hélia G. Cardoso a , Alejandro Hernández a , Augusto A. Peixe ${ }^{a, b}$, Alexios Polidoros ${ }^{\text {c }}$, \\ Alexandre Ferreira ${ }^{a}$, António Cordeiro ${ }^{\mathrm{d}}$ and Birgit Arnholdt-Schmitt ${ }^{\mathrm{a},{ }^{,}}$ \\ a ICAAM, University of Évora, 7002-554Évora, Portugal \\ ${ }^{\mathrm{b}}$ Department of Plant Production, ICAAM, University of Évora, 7002-554Évora, Portugal \\ ${ }^{c}$ Institute of Agrobiotechnology, Center for Research and Technology Hellas, Thermi, Greece \\ d INRB/ L-INIA, URGEMP. Apartado 6, 7350-Elvas, Portugal \\ Correspondence to *e-mail: eu_chair@uevora.pt
}

\begin{abstract}
Olive (Olea europaea L.) trees are mainly propagated by adventitious rooting of semi-hardwood cuttings. However, efficient commercial propagation of valuable olive tree cultivars or landraces by semi-hardwood cuttings can often be restricted by a low rooting capacity. We hypothesize that root induction is a plant cell reaction linked to oxidative stress and that activity of stress-induced alternative oxidase (AOX) is importantly involved in adventitious rooting. To identify AOX as a source for potential functional marker sequences that may assist tree breeding, genetic variability has to be demonstrated that can affect gene regulation. The paper presents an applied, multidisciplinary research approach demonstrating first indications of an important relationship between AOX activity and differential adventitious rooting in semi-hardwood cuttings. Root induction in the easy-to-root Portuguese cultivar 'Cobrançosa' could be significantly reduced by treatment with salicyl-hydroxamic acid, an inhibitor of AOX activity. On the contrary, treatment with $\mathrm{H}_{2} \mathrm{O}_{2}$ or pyruvate, both known to induce AOX activity, increased the degree of rooting. Recently, identification of several $O$. europaea $(\mathrm{Oe}) A O X$ gene sequences has been reported from our group. Here we present for the first time partial sequences of OeAOX2. To search for polymorphisms inside of OeAOX genes, partial OeAOX2 sequences from the cultivars 'Galega vulgar', 'Cobrançosa' and 'Picual' were cloned from genomic DNA and cDNA, including exon, intron and 3'-untranslated regions (3'-UTRs) sequences. The data revealed polymorphic sites in several regions of OeAOX2. The 3'-UTR was the most important source for polymorphisms showing $5.7 \%$ of variability. Variability in the exon region accounted 3.4 and $2 \%$ in the intron. Further, analysis performed at the cDNA from microshoots of 'Galega vulgar' revealed transcript length variation for the 3'-UTR of OeAOX2 ranging between 76 and $301 \mathrm{bp}$. The identified polymorphisms and 3'-UTR length variation can be explored in future studies for effects on gene regulation and a potential linkage to olive rooting phenotypes in view of marker-assisted plant selection.
\end{abstract}

Received 20 May 2009; revised 23 September 2009

DOI: $10.1111 / j .1399-3054.2009 .01302 . x$

Full article available: http://www3.interscience.wiley.com/journal/122618575/abstract 